Wear, Volume 258, Issues 1-4, January 2005, Pages 349-356

Second International Conference on Erosive and Abrasive Wear

\title{
The effect of TBC morphology on the erosion rate of EB-PVD TBCs
}

\author{
R.G. Wellman* ${ }^{\text {I }}$, M.J. Deakin ${ }^{2}$, J.R. Nicholls ${ }^{1}$ \\ ${ }^{1}$ Cranfield University, UK; ${ }^{2}$ Rolls Royce plc, UK. \\ r.wellman@.cranfield.ac.uk
}

Since thermal barrier coatings (TBCs) have been used in gas turbines most of the research conducted on them has involved the bond coat and the growth of the thermally grown oxide (TGO) as failure of the bond coat and the TGO were considered to be the primary causes of failure. Erosion of TBCs has been considered as a secondary problem and as such received less attention. Most of the initial work on the erosion of TBCs covered the effects of velocity and impact angle on the erosion rates of both plasma sprayed (PS) and electron beam physical vapour deposited (EB PVD) TBCs and compared the differences between the two deposition systems. Most of the tests were conducted on coatings in the as received condition.

This paper aims at expanding the understanding of the erosion of EB PVD TBCs by examining the effects of TBC morphology, column diameter, column inclination angle and the effects of aging and sintering on the erosion rates of EB PVD TBCs. Monte Carlo Modelling and mapping of EB PVD TBCs is also briefly discussed along with the associated mechanisms.

It was found that, all else being equal, erosion rate decreases with a decrease in the column diameter, while aging results in an increase in the erosion rate, dependant on the aging temperature and time. A decrease in the inclination angle of the columns with respect to the substrate increases the erosion rate, when the inclination angle is less than $60^{\circ}$ the erosion rate increases catastrophically. These effects are all discussed and explained in terms of erosion mechanisms and mechanical properties in the paper.

Keywords: Thermal Barrier Coatings, Erosion, Aging, Morphology 


\section{Introduction}

Since their introduction to service in gas turbine engines most of the research on thermal barrier coatings (TBCs) has concentrated on the bond coat and the thermally grown oxide (TGO), specifically in the form of thermal cyclic life ${ }^{1-4}$, or on the thermal conductivity of the ceramic top coat ${ }^{5-7}$. Erosion of TBCs, while acknowledged as a problem ${ }^{8 ; 9}$, was considered a secondary cause of failure and hence received less attention. Most of the initial work on the erosion of TBCs was based on comparative studies of plasma sprayed (PS) and electron beam (EB) physical vapour deposition (PVD) TBCs or the effects of impact conditions i.e impact velocity, impact angle and particle size. With most of the papers reporting the measured erosion rates ${ }^{10-13}$, and only a few touching on the actual erosion mechanisms $\mathrm{s}^{6 / 14-16}$.

More recently there has been an interest in the erosion mechanisms of TBCs particularly EB PVD TBCs. Since EB PVD TBCs are more strain tolerant than PS TBCs they have been used on turbine blades (a more highly stresses component) in the hot gas stream where they are subjected to higher impact velocities and higher impact angles, hence making erosion a possible life limiting problem. These developments have resulted in research aimed at understanding the erosion mechanisms of EB PVD TBCs ${ }^{15}$ to enable the development of predictive models ${ }^{17}$ which can be used to develop more erosion resistant coatings. EB PVD TBCs have a unique columnar microstructure which not only adds strain tolerance to the system ${ }^{8: 9}$ but also acts as an effective inhibitor to crack propagation ${ }^{16}$.

Previous studies of brittle erosion have shown that material removal occurs via the formation and intersection of cracks ${ }^{18-20}$. However, in EB PVD TBCs, due to the independent nature of the columnar microstructure, cracks, initiated in one column, do not intersect with each other or indeed with the top surface. Previous work conducted at Cranfield University ${ }^{14-17 ; 21-24}$ has shown that there are number of distinct mechanisms by which TBCs erode. These depend primarily on three factors, namely particle impact energy, which is dependent on particle size, density and velocity (erosion or foreign object damage), particle temperature (is the impacting particle, solid or in a semi-molten state 
i.e. 'pasty') and microstructure (the important point being whether the coating is an EB PVD or a PS TBC). As far as the authors are able to ascertain all of the erosion tests reported in the literature, see review by Jaslier et al ${ }^{14}$, were conducted on the samples in the as received condition, i.e. the coatings, which usually operate at temperatures of 950 to $1100^{\circ} \mathrm{C}$, had never been at temperature for any length of time prior to erosion testing within laboratory studies.

This paper aims at furthering the understanding of the erosion mechanisms of EB PVD TBC by bringing together the work on the erosion of EB PVD TBCs that has been undertaken at Cranfield University into one consolidated paper and will concentrate on the most recent work and work that has not been published before. Recent areas of study include the effects of TBC morphology, namely column size and inclination angle, and the effects of aging on the erosion rates of EB PVD TBCs. Discussion of the erosion map will highlight the recent discovery of an intermediate erosion mechanism, which operates between erosion and foreign object damage, and has been termed compaction damage.

All the erosion tests reported in this paper were conducted in the high temperature erosion test facility at Cranfield University, the erosion tests were carried out at room temperature while the FOD tests were carried out at both room temperature and $800^{\circ} \mathrm{C}$. Erosion studies at high temperature have previously been published as has a description of the rig, its capabilities and test ranges ${ }^{14 ; 24}$.

\section{EB PVD TBC Erosion Maps and Mechanisms}

Before discussing the effects of TBC morphology on the erosion rates of EB PVD TBC the erosion mechanisms of the coatings needs to be briefly discussed. Until recently erosion of EB PVD TBCs was divided into two main categories namely near surface cracking ${ }^{15}$ and foreign object damage ${ }^{14}$. The conditions under which these two mechanisms operate have been mapped ${ }^{17 ; 21}$ and can be related to both particle size and velocity. However, recent unpublished work by the authors has identified an intermediate mechanism, which operates between erosion and foreign object damage, termed 
compaction damage. The erosion map has been developed through a combination of modeling and experimental work and is illustrated in Figure 1. Initially developed as part of a project aimed at developing a Monte Carlo model to predict the erosion rates of EB PVD TBC under various erosion conditions, the map was used to identify the impact conditions under which the Monte Carlo model could be used to predict erosion rates. This Monte Carlo erosion model development was successful but is only valid for Mode I type erosion damage. Its derivation and application has been published previously ${ }^{16 ; 17}$. The model uses Monte Carlo statistics, material properties and fracture mechanics to calculate the erosion rate of EB PVD TBCs under Mode I impact conditions which can be specified by the user. The model has been validated against experimental results and was found to be accurate to within $20 \%$. The model is capable of predicting how the erosion rate will change with changes in material and system parameters, for example column diameter or impact angle.

The following sections give an overview of the different types of damage mechanisms that have been observed in EB PVD TBCs to date. These mechanisms are not mutually exclusive and it is expected that there will be a certain degree of overlap between the various mechanisms as this reflects the variation in impact particle size/velocity for any given impact experiment.

Mode I - Erosion (Lateral Cracking/Near surface cracking)

This occurs when engine generated particles, generally small particles with low energy, impact the $\mathrm{TBC}$ and results in the near surface region, the top $20 \mu \mathrm{m}$, of the individual columns cracking. Material is lost when a number of neighbouring columns have been impacted and cracked. It has been proposed that the cracks initiate at the elastic/plastic transition that occurs under the impacting particles ${ }^{15 ; 21}$, this type of near surface cracking is illustrated in Figure 2.

\section{Mode II - Compaction Damage}

This is a damage mechanism, intermediate between small particles erosion and FOD and may act as 
the transition between these two mechanisms, where there is compaction of the EB PVD TBC columns but neither the near surface cracking of Mode I nor the gross plastic deformation, kinking and cracking of Mode III (FOD) is observed. Column compaction, but not fracture occurs, resulting from the surface impact and is attributed to the high porosity levels in the columns and the lower stain rates associated with the impact. The columns of these coatings are less than $90 \%$ dense. A similar type of compaction occurs during Mode I, where the damage is limited to the near surface region of one or two columns and lateral cracks then initiate from the elastic/plastic interface. However, when the impact is spread over a significant number of columns, as is Mode II compaction damage, cracks do not initiate at this interface as shown in Figure 3. This thought to be due to a lower rate of energy input by the decelerating particle, resulting in a lower strain rate.

This mechanism is still under investigation but it is evident from the initial single impact studies that the Mode II damage mechanism is different form the other two and that cracking does not occur under single impacts. Multiple impacts studies are underway to determine the exact material removal mechanism that is operating under Mode II conditions.

Mode III - Foreign Object Damage (FOD)

FOD is caused by large particles travelling at low velocities and intermediate velocities or smaller particles at higher velocities and is characterised by significant deformation of the coating which can penetrate to the substrate and is accompanied by gross plastic deformation of the columns ${ }^{14}$ as illustrated in Figure 4. Within a gas turbine engine high velocity foreign object damage may result, when the rotating turbine blades impact slower moving large particles.

Work at Cranfield University has shown that there are in fact 2 distinct types of FOD. FOD Type 1 is the classically accepted mechanism of gross plastic deformation of the coating with the associated densification bending and cracking of the columns as shown in Figure 5 (a). The micrograph in 
Figure 5 (b) is of interest. It answers the question as to whether or not EB PVD TBCs can deform plastically at elevated temperatures, in this case $800^{\circ} \mathrm{C}$ and suggests a second type of foreign object damage needs to be defined. This has been termed FOD Type 2 and involves significant buckling of adjacent columns and plastic deformation without any significant degree of cracking.

The different Modes of damage discussed in this section are not purely dependent on impact velocity and particle size but rather the relative size of the contact footprint to the column diameter and the strain rates that result during the period of contact. Of course the contact footprint is directly related to the mass/size of the impacting particle and its velocity as well as material properties. Thus, in its present form, the erosion map (illustrated in Figure 1) is strictly only valid for a certain column diameter, in this case approximately $15 \mu \mathrm{m}$.

\section{Erosion Testing of Structurally Modified EB PVD TBCs}

The micrograph in Figure 6 illustrates the columnar microstructure that is typical of EB PVD TBCs. It is this microstructure that gives them their strain tolerance as well as their erosion resistance. During erosion the column boundaries act as crack inhibitors and thus any damage initiated in a column will be completely contained within the column as illustrated in Figure 2 earlier. Thus all other properties being equal, specifically: density, hardness, elastic modulus and fracture toughness, the TBC with the smaller column diameter is expected to have a lower erosion rate. This is due to the fact that less material will be lost per cracked column if they are smaller, thus to loose a similar amount of material per impact cracks will need to be initiated in more columns. This reduction in erosion rate with a decrease in the column diameter is also predicted by the Monte Carlo model ${ }^{21}$ as illustrated in Figure 7, although it is expected that a limit on this effect may exist, when an impacting particle can fracture a cluster of adjacent columns. In order to verify this it was decided to produce coatings with a smaller diameter than the standard $15 \mu \mathrm{m}$. This was achieved by making slight changes to the deposition parameters in the EB coating system. Table 1 outlines the different 
deposition conditions and gives the erosion rates at room temperature, with the column diameter in parentheses. The samples were all erosion tested at room temperature using $100 \mu \mathrm{m}$ alumina grit as the erodent.

When compared to the erosion rate of a 'standard' EB PVD TBC of $20 \mathrm{~g} / \mathrm{kg}{ }^{14} \mathrm{under}$ the same erosion conditions one can see that the modified structures have improved the erosion resistance of the coatings by a factor of two. It should be noted that in this study, two different types of microstructure were produced. Samples that were rotated, during the deposition process, had the "classic" columnar microstructure but of smaller column diameter. Those produced under a static condition were both thicker and the sample produced with $\mathrm{Ar}+90 \% \mathrm{O}_{2}$ ion bombardment was denser. Both the finer columnar microstructure and a more dense surface structure look beneficial in reducing the erosion rate.

Monte Carlo modelling of erosion behaviour has been undertaken using the material properties of a standard EB-PVD TBC. For a $15 \mu \mathrm{m}$ diameter column the model predicts an erosion rate of $14-15$ $\mathrm{g} / \mathrm{kg}$ this decreases to $7.8-8.3 \mathrm{~g} / \mathrm{kg}$ when the column diameter is reduced to $8 \mu \mathrm{m}$ and to $3.8-4.0 \mathrm{~g} / \mathrm{kg}$ when the column diameter is reduced to $6 \mu \mathrm{m}$, this is illustrated graphically in Figure 7. However, it must be noted that the model was not designed to deal with such small column diameters. Thus although the decrease in erosion rate with column diameter is expected to continue it is thought that the model may under-predict the erosion rate for columns less than $7 \mu \mathrm{m}$ in diameter. The fact that the sample with a $16 \mu \mathrm{m}$ diameter column also had a lower erosion rate implies that the reduction in erosion rate is not entirely due to changes in the column diameter. It is most likely that the increased densification observed for the static samples will alter the hardness and the fracture toughness of the columns and thus column properties should be expected to be affected by the change in deposition process. It will be necessary to measure the nano hardness of the columns to determine any changes in the material properties of the coatings to verify this hypothesis 


\section{Effect of Angle on Erosion of EB PVD TBCs}

There are two different concepts that will be discussed here: the effect of impact angle of the erodent and the effect of the inclination of the columns. The effect of the impact angle of the particle stream on an EB PVD TBC is as would be expected for a typical ceramic, with erosion rate increasing with and increase in impact angle with the maximum erosion rate being at about $90^{\circ}$ impact.

The Monte Carlo model predicts an increase in erosion rate with impact angle and correlates well to the experimental results, illustrated in Figure 8. These results are all for coatings where the columns are perpendicular to the substrate. However, if the particle stream is kept at $90^{\circ}$ to the substrate and the columns are grown at an angle to the substrate the opposite effect is observed. The erosion rate increases significantly as the inclination angle between the columns and the substrate decreases; this is illustrated graphically in Figure $9 \mathrm{a}$ and $\mathrm{b}$.

It was expected that by inclining the columns relative to the substrate, Figure 10, the thermal conductivity of the TBC would decrease due to the added phonon scattering that would be obtained from the inclined column boundaries. This was found to be the case however the detrimental effects on the erosion resistance meant that this method could not be used as a means of decreasing the thermal conductivity. As can be seen from the graphs at inclination angles less than $70^{\circ}$ there is a significant increase in the erosion rate and at inclination angles less than $50^{\circ}$ the erosion rate is greater than that of plasma sprayed coatings. The increase in the erosion rate was attributed to the fact that under impact conditions the columns would bend causing cracks to initiate from edge defects, dendrites, in the columns. These cracks initiate deeper in the coating than Mode I type damage thus resulting in a greater loss per impact. Further, as the inclination angle decreases the depth at which cracking initiated also increased. 


\section{The Effect of Aging on the Erosion of EB PVD TBCs}

In order to determine the effect of aging on the erosion rate of EB PVD TBCs, a number of samples were heat treated under various conditions, Table 2, before erosion testing at room temperature. $1100^{\circ} \mathrm{C}$ is representative of the normal expected service conditions while $1500^{\circ} \mathrm{C}$ would ensure that sintering of the columns occurred, within a reasonable exposure time, this is illustrated in Figure 11 where sintering of the columns can clearly be seen. When engines operate under extreme conditions hotspots can develop in the engine resulting in localised sintering of the TBC surface. One must remember that in service TBCs operate in a temperature gradient with the outer ceramic surface hotter than the bond coat / ceramic interface. By aging the samples at $1500^{\circ} \mathrm{C}$ it would be possible to see what effect sintering has on the erosion rate of EB PVD TBCs. The samples were eroded at room temperature using $100 \mu \mathrm{m}$ angular alumina particles for six exposures of $30 \mathrm{~s}$ each, erosion rate is reported as grams of coating removed per kilogram of impacting alumina.

As can be seen from the results in Figure 12 the heat treatments resulted in dramatic increases in the erosion rates of the EB PVD TBCs. In the case of the samples aged at $1500^{\circ} \mathrm{C}$ for $24 \mathrm{~h}$ the almost four fold increase in erosion rate was attributed to the sintering together of the columns. Since in Mode I erosion, column boundaries act as inhibitors to crack propogation, when the columns sinter together the cracks initiated due to particle impact can propagate into neighbouring columns resulting in a greater volume loss per impact.

The samples heat treated at $1100^{\circ} \mathrm{C}$ for $100 \mathrm{~h}$ also showed a significant increase in erosion rate. However, these samples showed no evidence of sintering and the increase in erosion rate is attributed to the changes in the shape of the micro porosity of the columns affecting the hardness and the fracture toughness of the EB PVD TBC columns. 


\section{Effect of Vertical Micro-cracks of the Erosion Rate of APS TBCs}

For completeness sake the effect of introducing pseudo-columns into air plasma sprayed APS TBCs, by the introduction of vertical micro-cracks into the coatings will also be discussed briefly*. This is not entirely out of place here as it is the morphology/properties of the individual columns that determines the erosion rate of EB PVD TBCs. Thus by introducing vertical micro cracks into APS TBCs and producing 'columns' some of the advantages of EB PVD coatings can be realised in APS coatings, as evidenced by the reduction in the erosion rate of the vertically cracked coatings compared to the conventional APS coatings.

It is generally accepted that APS TBCs have an erosion rate significantly higher than that of EB PVD TBCs, which is partly due to the differences in the erosion mechanisms of the two coatings. It has been proposed ${ }^{23}$ that material loss in APS TBCs is in the form of the removal of whole 'splats' from the coating. Impacting particles initiate cracks at the 'splat' boundaries these cracks then propagate along the boundary resulting in the loss of the whole splat. However, as can be seen from the results in Table 3 by introducing vertical micro-cracks into an APS TBC the erosion rate can be reduced by a factor of four to five, when compared to a standard APS TBC, which brings it down to a level similar to that of standard EB PVD TBCs. This increase in erosion resistance is attributed directly to the micro-cracks, which act to inhibit crack propagation through the coating thus reducing the amount of material lost per impact.

\section{Summary and Conclusions}

It has become clear that the morphology of the individual columns plays a major role in determining the erosion rate of EB PVD TBCs. Thus any process which affects the morphology of the individual columns of the coating is likely to affect the erosion rate. In each of the scenarios examined in this

\footnotetext{
* The vertically micro-cracked PS TBCs were supplied to Cranfield University by CESI, Italy as part of work undertaken in Cost 522.
} 
paper the physical and/or the mechanical properties of the columns was altered resulting in an associated increase or decrease in erosion rate.

- Three different erosion mechanisms (Modes) have been identified and discussed.

- The erosion Mode is dependent on a combination of particle size and impact velocity as well as coating microstructure and the column diameter.

- $\quad$ EB PVD TBCs have a maximum erosion rate at approximately $90^{\circ}$ impact.

- A change to the column's microstructure has a significant affect on the erosion resistance of the coating.

- As the inclination of the columns of EB PVD TBCs decrease from normal to the substrate the erosion rate increases.

- It has been shown that thermal aging will increase the erosion rate of EB PVD TBCs when compared to as coated samples.

- From preliminary studies it appears that aging at $1500^{\circ} \mathrm{C}$ for $24 \mathrm{hrs}$ increases the erosion rate by a factor of 4 , due to the partial sintering of the columns enabling crack propagation across neighbouring columns to occur resulting in a greater volume loss per impact.

- Aging at $1100^{\circ} \mathrm{C}$ for $100 \mathrm{hrs}$ increased the erosion rate by a factor of 2 although no evidence of column sintering could be observed. This increase in erosion rate was attributed to changes in the micro-porosity of the columns and sub-columns.

- The introduction of vertical micro-cracks into APS TBCs result in a four fold decrease in erosion rate, due to the pseudo columns produced inhibiting the propagation of lateral cracking.

\section{Acknowledgements}

The work presented in this paper has been undertaken under a number of different projects at Cranfield University and the authors would like to thank the following organisations for their funding 
of the various projects; EPSRC, Rolls Royce Plc and the Hipercoat EU-NSF programme. The lead author would like to acknowledge the input that the late Prof A Ball had on his career. 


\section{Reference List}

1. T.A Cruse, S.E Stewart, and M Ortiz. Thermal Barrier Coating Life Prediction Model Development. Transactions of the ASME 110, 610-616 (1988).

2. B.C Wu, E Chang, S.F Chang, and C.H Chao. Thermal Cyclic Response of Yttria-Stabilised Zirconia/CoNiCrAlY Thermal Barrier Coatings. Thin Solid Films 172, 185-196 (1989).

3. J.H Sun, E Chang, B.C Wu, and C.H Tsai. The Properties and Performance of ( $\mathrm{ZRO}_{2}-$ $\left.8 \mathrm{wt} \% \mathrm{Y}_{2} \mathrm{O}_{3}\right) /\left(\mathrm{CVD} \mathrm{Al}_{2} \mathrm{O}_{3}\right) /(\mathrm{Ni}-22 \mathrm{wt} \% \mathrm{Cr}-10 \mathrm{wt} \% \mathrm{Al}-1 \mathrm{wt} \% \mathrm{Y})$ Thermal Barrier Coatings. Surface and Coatings Technology 58, 93-99 (1993).

4. D.M Nissley. Thermal Barrier Coating Life Modelling in Aircraft Gas Turbine Engines. Thermal Barrier Coatings Workshop NASA Conference Publication 3312 265-281 (1995).

5. R.B Dinwiddie, S.C Beecher, B.A Nagaraj, and C.S Moore. Thermal Conductivity of Zirconia Thermal Barrier Coatings. NASA Conference Publication 3312167 (1995).

6. J.R Nicholls, K.J Lawson, D.S Rickerby, and P Morrell. Advanced Processing of TBCs for Reduced Thermal Conductivity. Thermal Barrier Coatings Agard Report 823, Paper 6 (1998).

7. J.M Dorvaux et al. Modelling the Thermal Conductivity of Thermal Barrier Coatings. AGARD Report 823 (1998).

8. F.C Toriz, A.B Thakker, and S.K Gupta. Flight Service Evaluation of Therma Barrier Coatings by Physical Vapour Deposition at 5200H. Surface and Coatings Technology 39/40, 161-172 (1989).

9. P Morrel and D.S Rickerby. Advantages/Disadvantages of Various TBC Systems as Perceived by the Engine Manufacturer. AGARD Report 823 20-1 (1998).

10. T Rhys-Jones and F.C Toriz. Thermal Barrier Coatings for Turbine Use in Aero Engines. High Temperature Technology 7, 73-81 (1989).

11. W Tabakoff and V Shanov. Erosion Rate Testing at High Temperature for Turbomachinery Use. Surface and Coatings Technology 76-77, 75-80 (1995).

12. A.G Davis, D.H Boone, and A.V Levy. Erosion of Ceramic Thermal Barrier Coatings. Wear 110, 101-116 (1986).

13. F.C Toriz, A.B Thakker, and S.K Gupta. Thermal Barrier Coatings for Turbine Applications in Areo Engines. High Temperature Technology 7, 1-11 (1989).

14. J.R Nicholls, Y Jaslier, and D.S Rickerby. Erosion and Foreign Object Damage of Thermal Barrier Coatings. Materials Science Forum 251-254, 935-948 (1997).

15. R.G Wellman and J.R Nicholls. Some Observations on the Erosion Mechanism of EB PVD TBCs. Wear 242, 89-96 (2000).

16. R.G Wellman and J.R Nicholls. A Mechanism for the Erosion of EB PVD TBCs. Materials Science Forum 369-372, 531-538 (2001).

17. R.G Wellman and J.R Nicholls. Modelling the Erosion of EB PVD TBCs. Euromat 2001. 2001.

18. A.W Ruff and S.M Wiederhorn. Treatise of Materials Science. C.M Preece. Treatise of Materials Science. 16, 69-. 79. Academic Press.

19. B.R Lawn and E.R Fuller. Equilibrium Penny-Like Cracks in Indentation Fracture. Journal of Materials Science 10, 2016-2024 (1975a).

20. A.G Evans and T.R Wilshaw. Dynamic Solid Particle Damage in Brittle Materials: An Appraisal. Journal of Materials Science 12, 97-116 (1977).

21. R.G Wellman. Modelling the Erosion of EB PVD TBCs. Ph.D. Thesis, Cranfield University (2001).

22. Y Jaslier. Erosion of Thermal Barrier Coatings. PhD Thesis, Cranfield University (1995).

23. J.R Nicholls, M.J Deakin, and D.S Rickerby. A Comparison between the Erosion Behaviour of Thermal Spray and EB PVD Thermal Barrier Coatings. Wear 233-235, 352-361. 99.

24. J.R Nicholls, Y Jaslier, and D.S Rickerby. Erosion of EB-PVD Thermal Barrier Coatings. Materials at High Temperature 15, 15-22 (1998). 
Figure 1: Erosion map for EB PVD TBCs.

Figure 2: Cross sections of eroded samples of TBCs showing near surface cracking, a) at room temperature and $\mathrm{b}$ ) at $800^{\circ} \mathrm{C}$.

Figure 3: Micrographs of single impact Mode II compaction damage showing compaction of the coating, note the absence of cracking, a) top view and b) cross section view.

Figure 4: Micrograph illustrating the effect of FOD in an EB PVD TBC, in both cases the damage was caused by a single impact, a) at room temperature and b) at $800^{\circ} \mathrm{C}$.

Figure 5: SEM micrographs illustrating FOD in EB PVD TBCs, a) Type 1 and b) Type2.

Figure 6: Micrograph of a fractured EB PVD TBC section illustrating the columnar microstructure.

Figure 7: The effect of column diameter on the erosion rate of EB PVD TBCs

Figure 8: Graph of erosion rate as a function of particle impact angle, predicted and experimental results.

Figure 9: Graphs showing the increase in erosion rate of EB PVD TBCs as the column inclination angle decreases.

Figure 10: SEM micrograph of a fracture section of an EB PVD TBC with inclined columns.

Figure 11: Cross section SEM micrograph of a TBC that has been eroded after a $24 \mathrm{~h} 1500^{\circ} \mathrm{C}$ heat treatment, the arrows in photo (b) indicate where the columns have started to sinter together.

Figure 12: Results of the erosion testing of the aged samples.

Figure 13: Micrographs of a vertically micro-cracked APS TBC. 


\begin{tabular}{|l|l|l|}
\hline & Ar- $90 \% \mathrm{O}_{2}$ & 6 min Ar only, then $\mathrm{Ar}-90 \% \mathrm{O}_{2}$ \\
\hline Rotated & $9.78(4.0)$ & $7.89(4.2)$ \\
\hline Static & $8.14(16.0)$ & $9.45(5.9)$ \\
\hline
\end{tabular}

Table 1: Table of deposition parameters and erosion rate (in $\mathrm{g} / \mathrm{kg}$ ) and column diameter in parentheses (in $\mu \mathrm{m}$ ). 


\begin{tabular}{|l|l|}
\hline Time & Temperatrue \\
\hline $30 \mathrm{~h}$ & $1100^{\circ} \mathrm{C}$ \\
\hline $100 \mathrm{~h}$ & $1100^{\circ} \mathrm{C}$ \\
\hline $24 \mathrm{~h}$ & $1500^{\circ} \mathrm{C}$ \\
\hline
\end{tabular}

Table 2: Heat treatment conditions. 


\begin{tabular}{|l|l|l|}
\hline Coating & Impact Angle $\left(^{\circ}\right)$ & $\begin{array}{l}\text { Erosion Rate } \\
(\mathrm{g} / \mathrm{kg})\end{array}$ \\
\hline Vertically cracked APS TBC & 30 & 9.5 \\
\hline Vertically cracked APS TBC & 90 & 24 \\
\hline Standard APS TBC & 30 & 48 \\
\hline Standard APS TBC & 90 & 118 \\
\hline
\end{tabular}

Table 3: Table of erosion rates for the different APS erosion tests. 


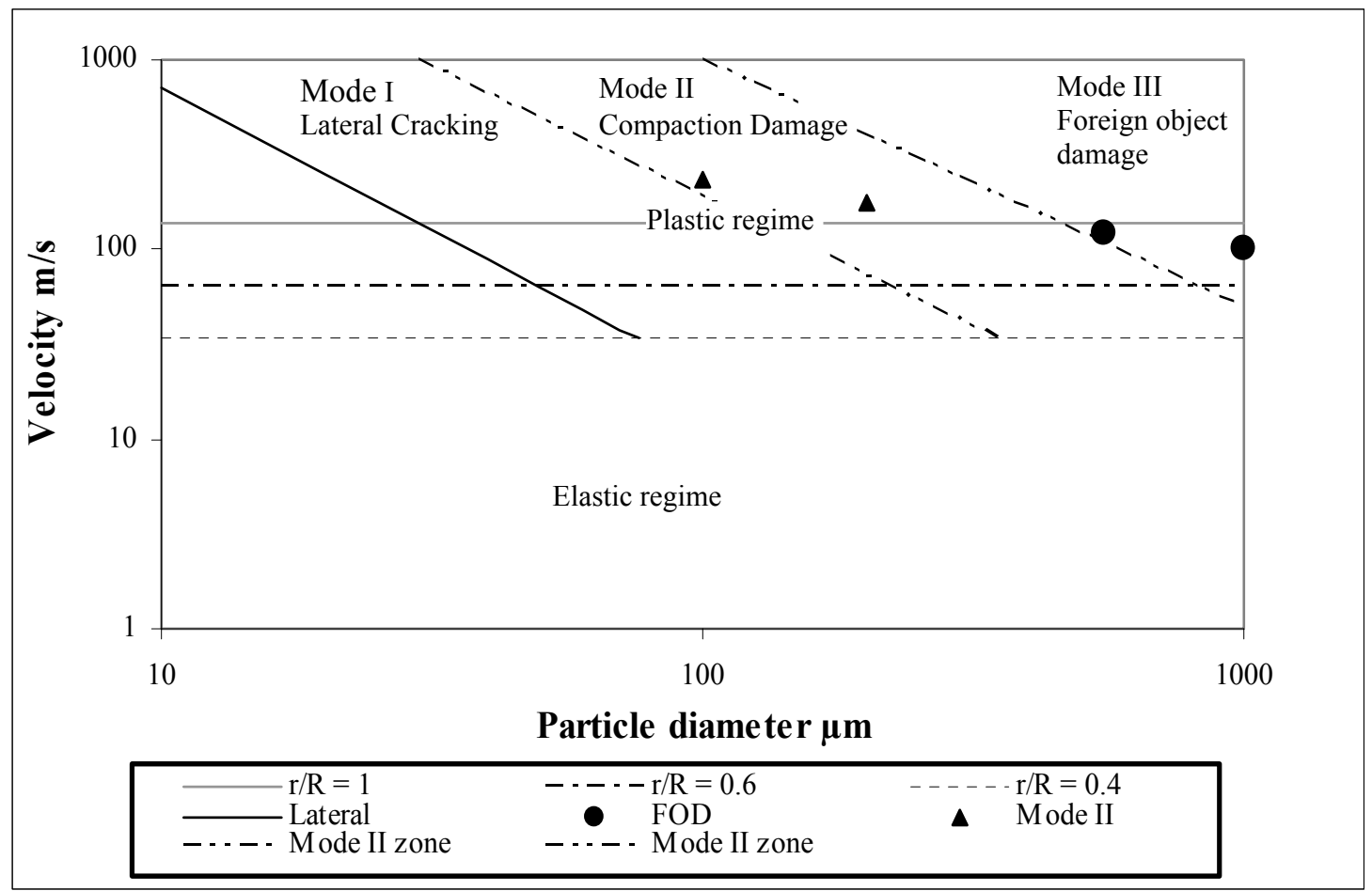

Figure 1: Erosion map for EB PVD TBCs. 


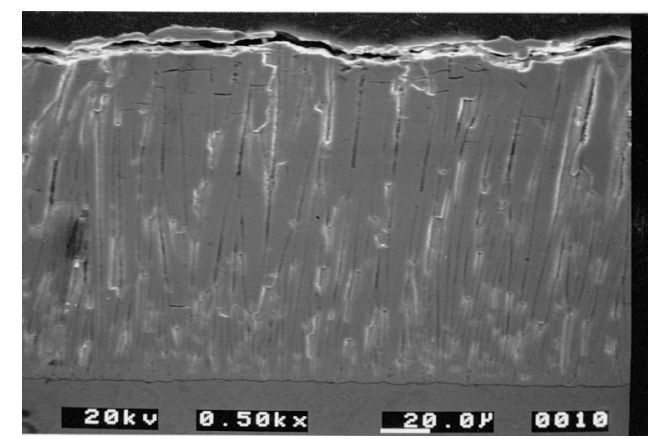

(a)

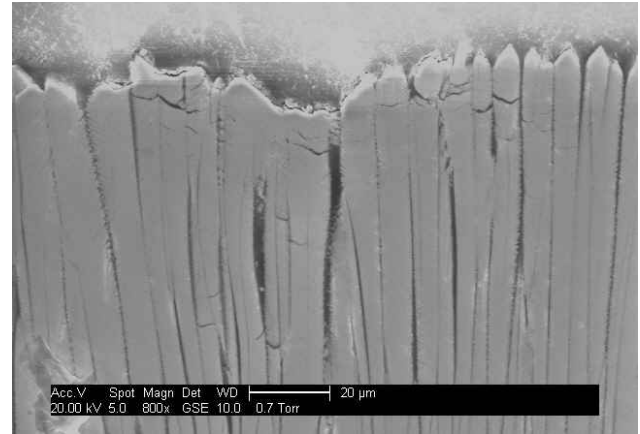

(b)

Figure 2: Cross sections of eroded samples of TBCs showing near surface cracking, a) at room temperature and $\mathrm{b}$ ) at $800^{\circ} \mathrm{C}$. 


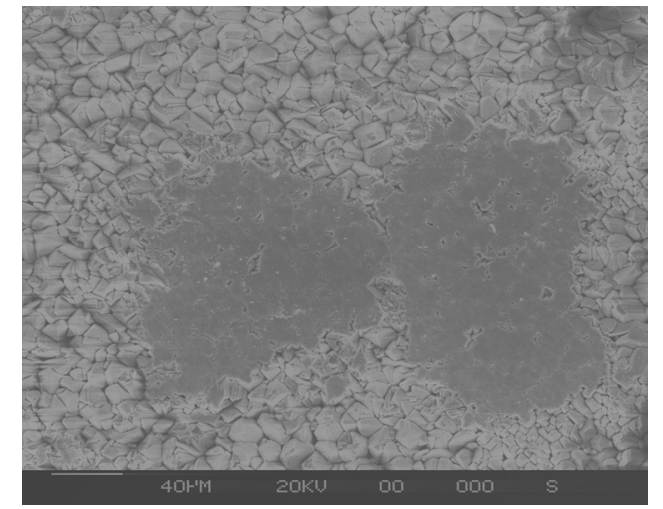

(a)

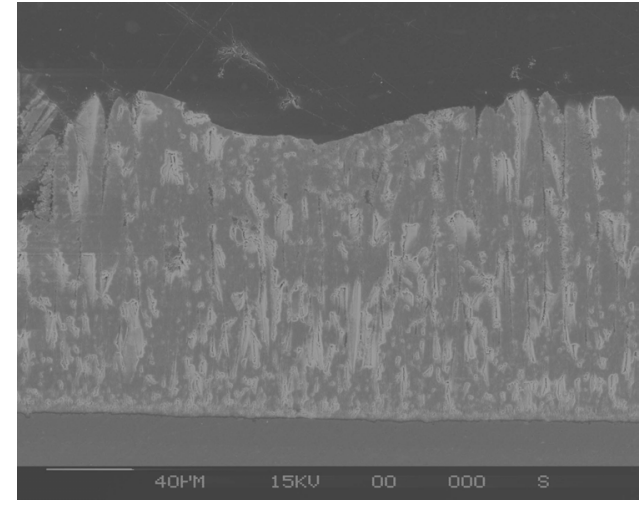

(b)

Figure 3: Micrographs of single impact Mode II compaction damage showing compaction of the coating, note the absence of cracking, a) top view and b) cross section view. 


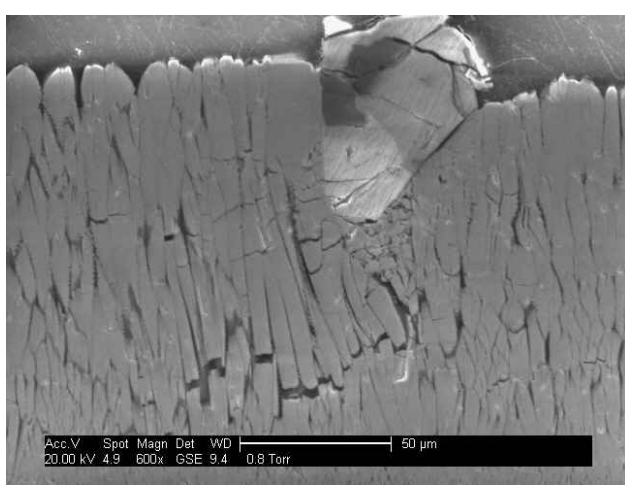

(a)

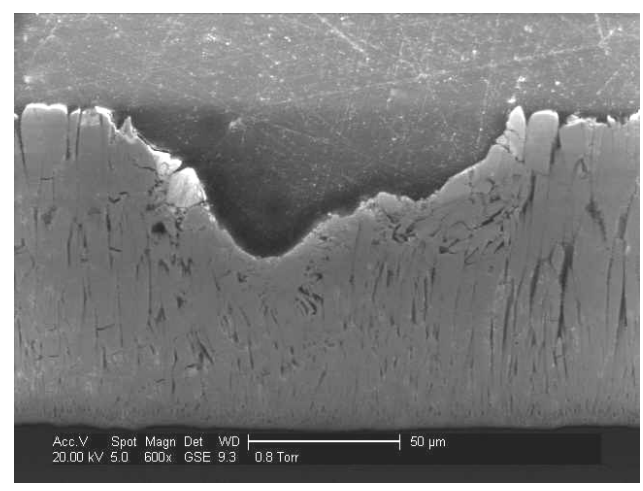

(b)

Figure 4: Micrograph illustrating the effect of FOD in an EB PVD TBC, in both cases the damage was caused by a single impact, a) at room temperature and b) at $800^{\circ} \mathrm{C}$. 


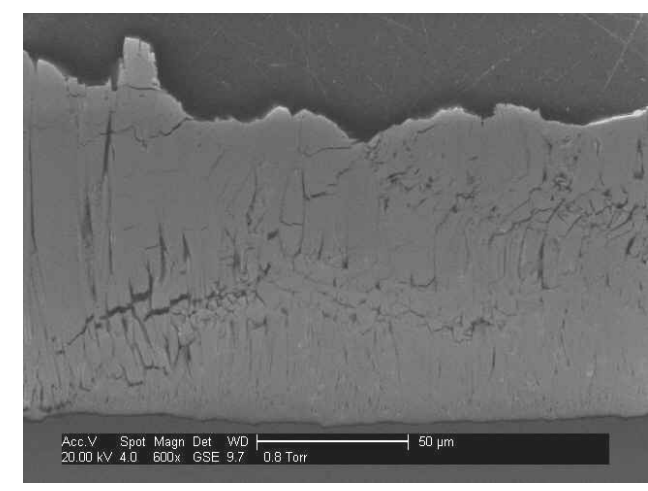

(a)

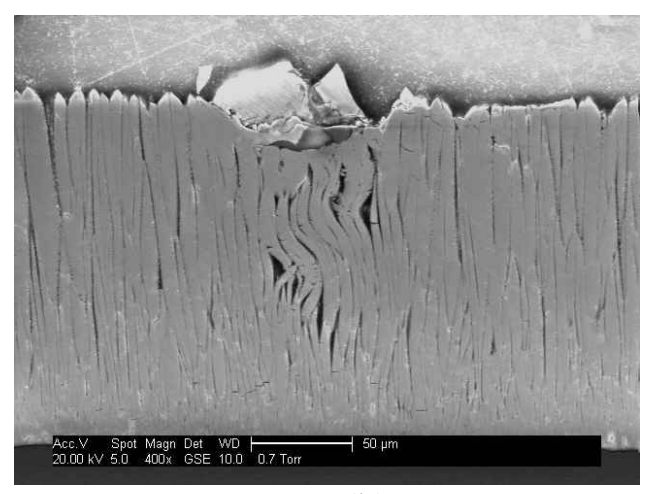

(b)

Figure 5: SEM micrographs illustrating FOD in EB PVD TBCs, a) Type 1 and b) Type2. 


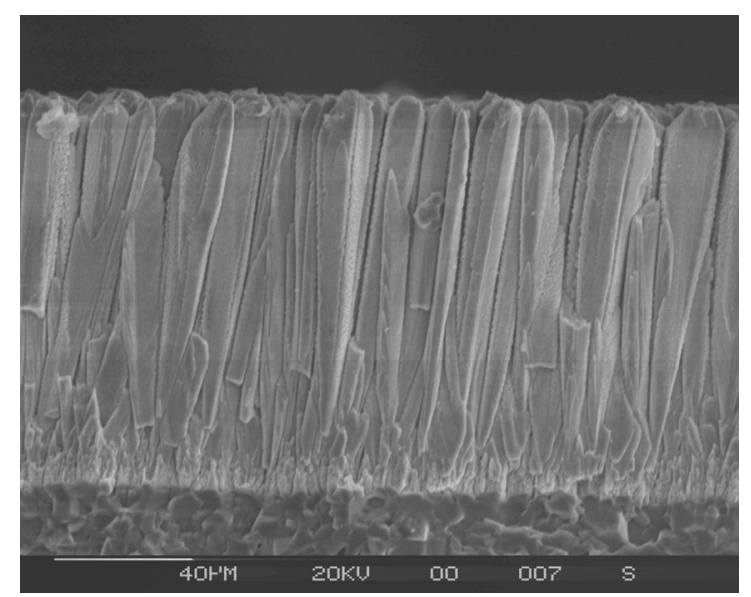

Figure 6: Micrograph of a fractured EB PVD TBC section illustrating the columnar microstructure. 


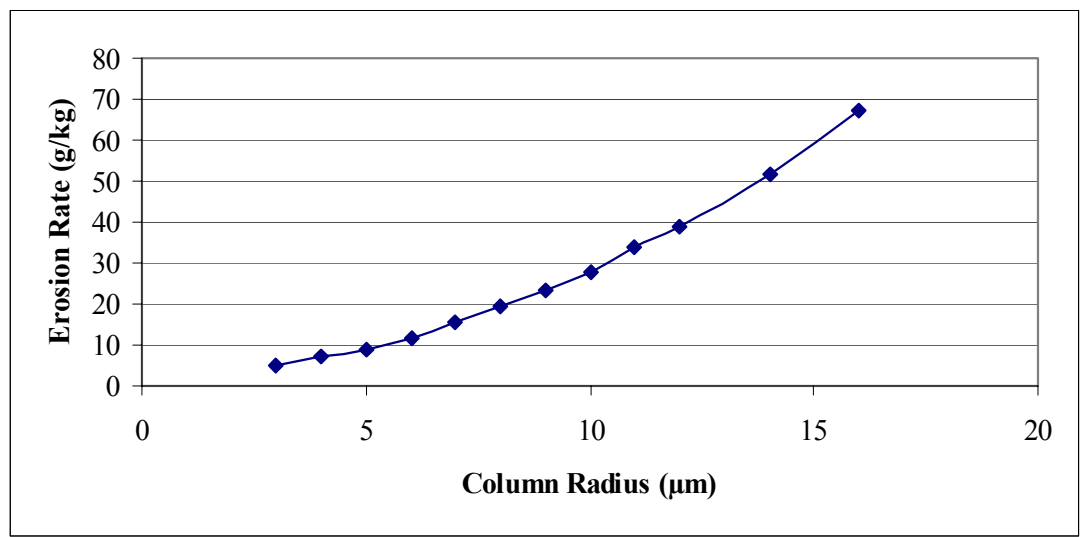

Figure 7: The effect of column diameter on the erosion rate of EB PVD TBCs 


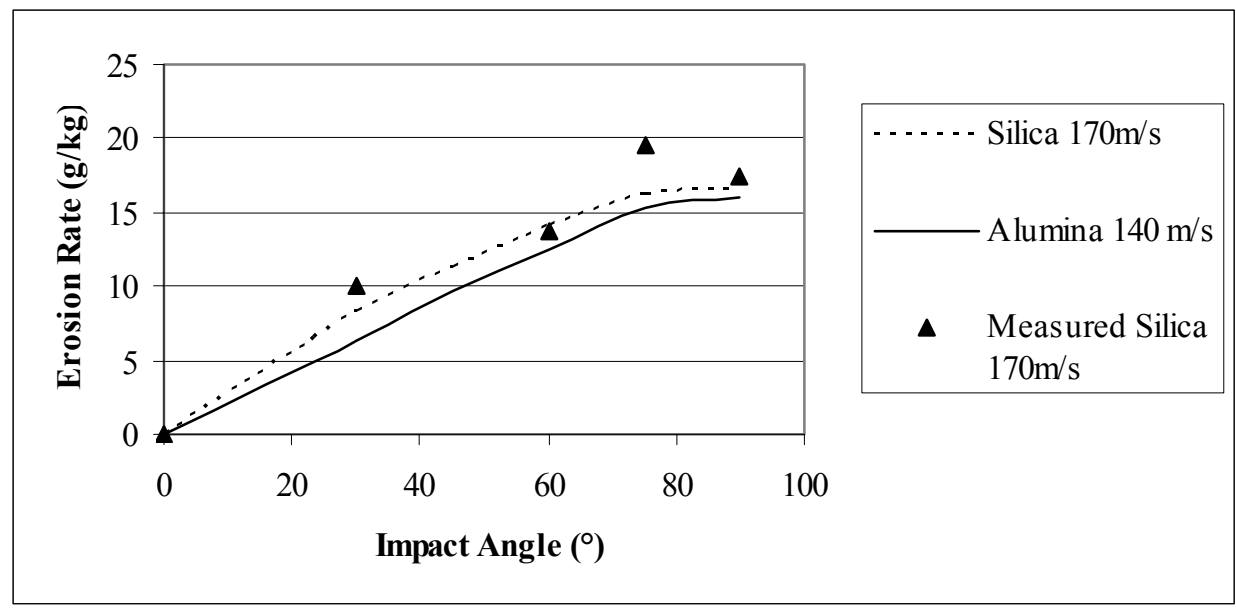

Figure 8: Graph of erosion rate as a function of particle impact angle, predicted and experimental results. 


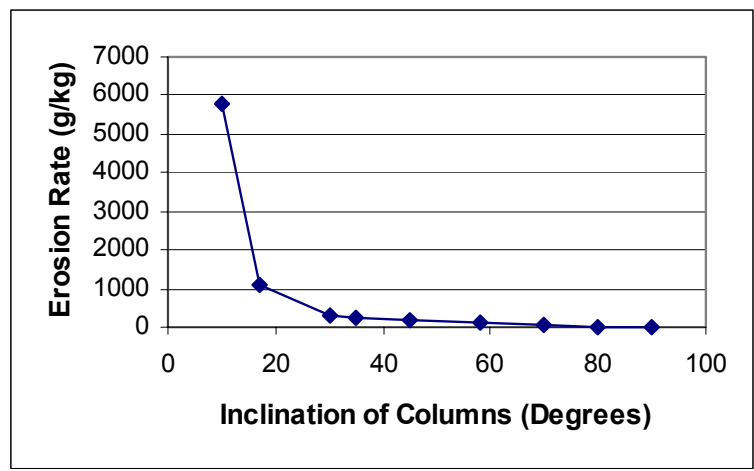

(a)

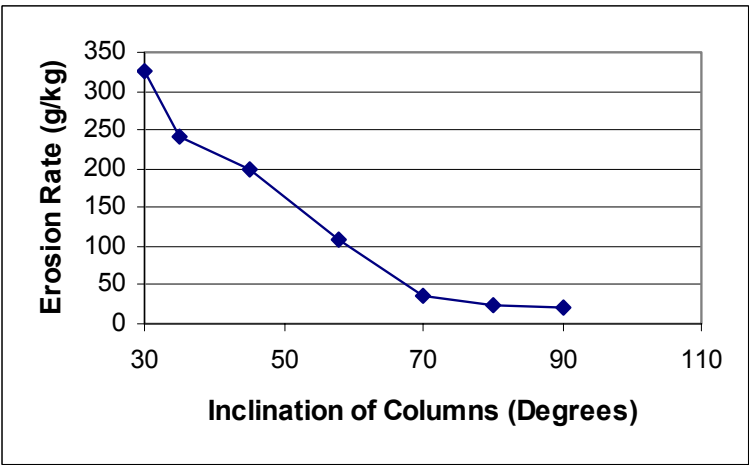

(b)

Figure 9: Graphs showing the increase in erosion rate of EB PVD TBCs as the column inclination angle decreases. 


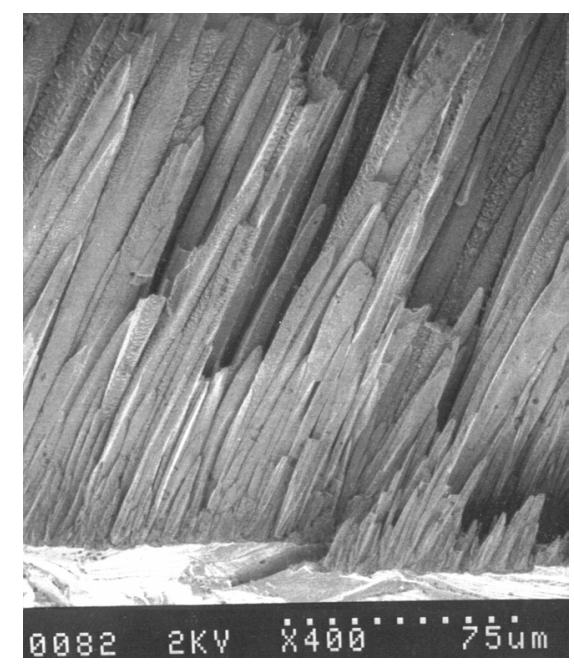

Figure 10: SEM micrograph of a fracture section of an EB PVD TBC with inclined columns. 


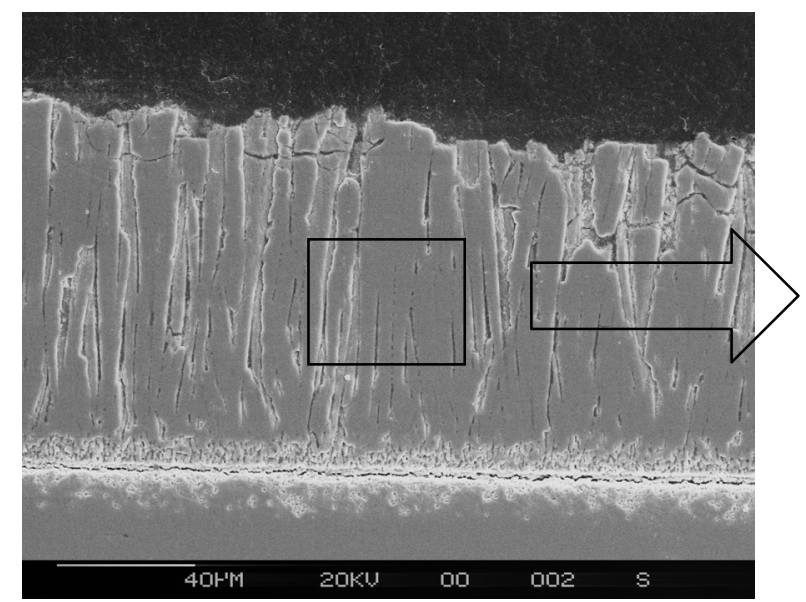

(a)

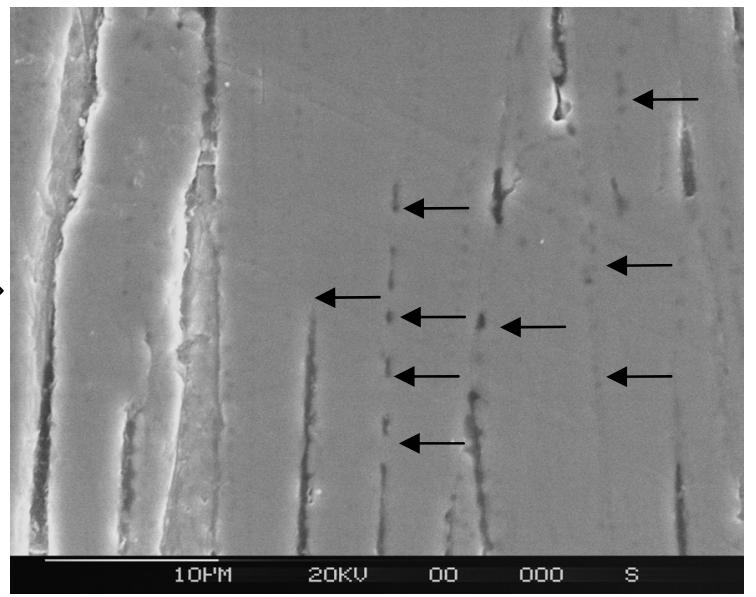

(b)

Figure 11: Cross section SEM micrograph of a TBC that has been eroded after a $24 \mathrm{~h} 1500^{\circ} \mathrm{C}$ heat treatment, the arrows in photo (b) indicate where the columns have started to sinter together. 


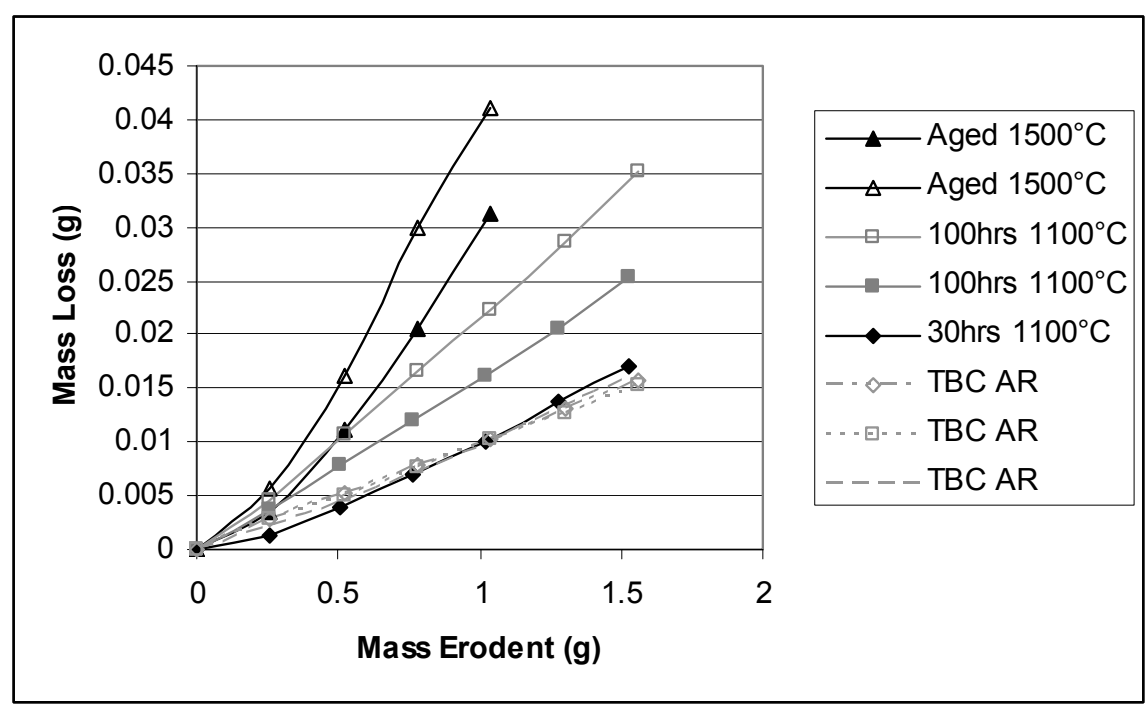

Figure 12: Results of the erosion testing of the aged samples. 


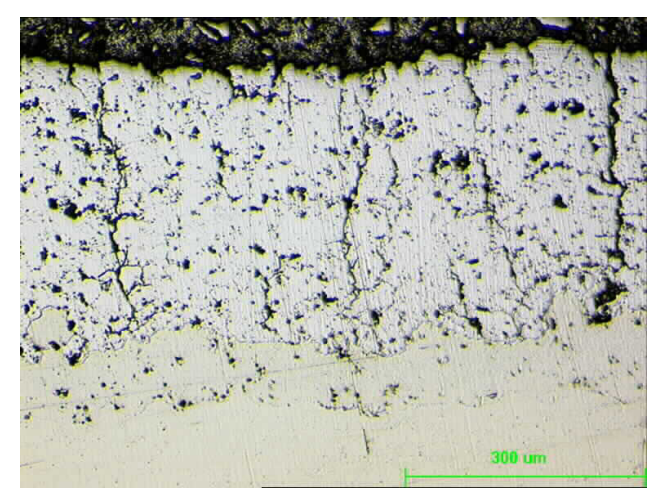

Figure 13: Micrographs of a vertically micro-cracked APS TBC. 